\title{
HIV Prevalence Comparison Between Antenatal Sentinel Surveillance and Demographic and Health Survey in Rwanda ${ }^{\S}$
}

\author{
Jeanne Françoise Kayibanda ${ }^{1,2}$, Michel Alary ${ }^{*}, 1,2,3$, Raphaël Bitera ${ }^{1,2,3}$, Adeline Kabeja ${ }^{4}$, \\ Ruton Hinda ${ }^{4}$, Louis Munyakazi ${ }^{5}$, Bassirou Chitou ${ }^{5}$ and Jean Philippe Gatarayiha ${ }^{5}$ \\ ${ }^{I}$ URESP, Centre de Recherche FRSQ du CHA Universitaire de Québec, Québec, Canada \\ ${ }^{2}$ Département de Médecine Sociale et Préventive, Université Laval, Québec, Canada \\ ${ }^{3}$ Institut National de Santé Publique du Québec, Québec, Canada \\ ${ }^{4}$ Rwanda Treatment and Research Aids Center, Kigali, Rwanda \\ ${ }^{5}$ Rwanda National Institute of Statistics, Kigali, Rwanda
}

\begin{abstract}
Objective: To compare HIV prevalence from antenatal surveillance to that of the demographic and health survey (DHS), and to identify factors determining the difference of HIV prevalence between women recruited in these two surveys in Rwanda in 2005.

Methods: Comparative cross-sectional study of HIV prevalence and socio-demographic factors collected by the antenatal survey in 13,745 pregnant women, seen in 30 health centres located throughout the country and those collected by the DHS among 5641 women, aged 15-49 years living in households located throughout the country. Log-binomial regression and direct standardization were used to estimate and compare HIV prevalence between the two surveys.

Results: HIV prevalence in the antenatal survey was slightly higher than that in DHS women $(4.1 \%$ versus $3.6 \% \mathrm{p}=0.103)$. Socio-demographic characteristics were differently distributed between the two populations. Whereas, $59 \%, 93 \%, 53 \%$ of pregnant women were aged 20-29 years, married or cohabiting and living in rural areas respectively, the corresponding proportions among DHS women were $35 \%, 48 \%$ and $83 \%(\mathrm{p}<0.001)$. Simultaneous standardization of antenatal prevalence according to the distribution of socio-demographic characteristics in the DHS gave an overall HIV prevalence estimate of $3.6 \%$, similar to the prevalence measured among DHS women.

Conclusions: HIV prevalence in the antenatal survey overestimated that among women of the general population in Rwanda in 2005. This overestimation could be corrected by standardization of antenatal prevalence according to the distribution of age, geographical area, marital status, parity, and education, in the general population.
\end{abstract}

Keywords: Rwanda, HIV prevalence, sentinel surveillance, demographic and health survey.

\section{INTRODUCTION}

For the last two decades sentinel surveillance was largely used as the main indicator for monitoring the progress of the HIV epidemic at the national level $[1,2]$.

However some studies showed that HIV prevalence among pregnant women overestimate that in women of the general population $[3,4]$, whereas other showed opposite results $[5,6]$.

Thus, national and global HIV prevalence and AIDS mortality estimates derived from HIV sentinel surveillance

\footnotetext{
*Address correspondence to this author at the Unité de recherche en santé des populations, URESP, Centre de recherche FRSQ du CHA universitaire de Québec, 1050 chemin Sainte-Foy, Québec (Québec), G1S 4L8 Canada; Tel: 1418682 7387; Fax: 1418682 7949; E-mail: malary@uresp.ulaval.ca

${ }^{\S}$ The abstract of this article was presented as a poster at the 18th Annual Canadian Conference on HIV Research which took place in Vancouver (Canada) from 23 to 26 April 2009 and at the $18^{\text {th }}$ International Conference on AIDS, which took place in Vienna (Austria) from 18 to 23 July 2010.
}

have been criticised because the sentinel population is often non representative of the general population.

Indeed, the poor functioning of HIV sentinel surveillance system in some sub Saharan African countries with generalized epidemics, among them Rwanda, explain in part why global HIV/AIDS estimates at the end of 2002 were higher than those reported in 2003 [7-9]; whereas UNAIDS and WHO revised the global estimate of the number of HIVinfected people from 39,5 million in 2006 to 33,2 million in 2007 partly for the same reason [10].

Since 2001 some low and middle-income countries have conducted population-based household surveys, the demographic and health surveys (DHS) which included HIV testing [11]. WHO/UNAIDS and some authors recommend that the countries in which these surveys are implemented use HIV national estimates to calibrate antenatal data, and use the combined national and antenatal data to estimate prevalence among the general population [12-14]. 
The first DHS including HIV testing was carried out in 2005 in Rwanda, whereas the HIV antenatal surveillance was improved in 2002 to ensure national coverage.

We compared HIV prevalence from these two sources of data as collected in 2005 , in order to validate the new antenatal surveillance program.

\section{DATA AND METHODS}

We obtained HIV data from the third DHS conducted by Macro International and the Rwanda National Institute of Statistics in 2005 [15] and from the ANC surveillance from Rwanda Treatment and Research Aids Center [16] collected the same year.

\section{Demographic and Health Survey}

In 2005, Rwanda organized its third DHS which was its first that included HIV testing. A national representative sample of 10644 households was selected using two-stage cluster sampling based on the list of the 2002 General Population and Housing Census.

All men and women of every second selected household were eligible for HIV testing. After informed consent blood samples were collected from all eligible men and women who volunteered to be tested in these households.

A laboratory technician collected capillary blood from finger prick on a filter paper, testing for HIV antibodies was performed at the National Reference Laboratory (NRL) in Kigali, using ELISA tests [15].

A face to face interview covered socio-demographic characteristics and other health issues including HIV related behaviour. Questionnaires were translated from English or French to local language (Kinyarwanda), and a pre-test was organized before the survey to validate them.

\section{The Sentinel Surveillance System}

The 2005 surveillance included 30 sites out of 372 health centers located all over the country: 2 sites in Kigali (Capital), 12 sites in other urban areas, and 16 sites in rural areas.

The sentinel sites were selected according to the number of pregnant women registered for their first antenatal visit (at least 80 new pregnant women per month), the availability of at least one laboratory technician and one midwife on site, the geographical accessibility of the site and the ability to accomplish the surveillance activities on a regular basis.

For all pregnant women attending ANC, a venous blood sample was taken for syphilis testing, and sera were anonymously tested for HIV, using the same laboratory algorithm as that used for the DHS specimens. For each woman, information was collected on socio-demographic factors.

For both DHS and ANC surveillance specimens, testing was done without any knowledge of the socio-demographic characteristics of participants. Socio-demographic and serologic data were matched by a unique survey code after completion of all serological testing.

\section{Statistical Analyses}

The SAS software (SAS Institute Inc., Version 9.1.3, Cary, NC, USA) was used for statistical analyses.

To make comparison between the two populations, we firstly merged the ANC and women DHS data set keeping the common variables: socio demographic (age, geographic area, schooling, marital status and number of children); and HIV status. We then created a new dichotomous variable comparison coded 1 for ANC population and 0 for DHS women.

We compared the distribution of socio-demographic characteristics of ANC and DHS women using the chisquare test. In order to determine which characteristics caused differences in HIV prevalence between the two populations we also carried out univariate and multivariate comparisons considering HIV status as the dependent variable and socio-demographic characteristics as the independent variables. The model included also the comparison variable. The ratio of HIV prevalence from DHS women to ANC women with $95 \%$ confidence intervals (CI) was used as the measure of association, whereas statistical testing was based on Wald chi-square tests from log binomial regression outputs. The proc genmod SAS procedure was used for this step.

To correct ANC bias and to estimate the overall HIV prevalence among women in the general population from the ANC data, we applied a direct standardization of HIV prevalence among ANC attendees according to the distribution of all socio-demographic characteristics common to both databases. We used proc freq SAS procedure for this analysis.

\section{Ethical Considerations}

For the DHS, an informed consent form was read to the eligible subjects or to parents/tutors of teenagers (aged 15 to 18 years); when the parent or tutor of a teenager agreed to the test, the form was read to the teenager to obtain his/her own consent to the HIV test.

HIV testing was entirely anonymous in the DHS and the study protocol was approved by ORC Macro's Internal Review Board and the National Ethics Committee in Rwanda. The testing protocol followed in the ANC survey is based also on unlinked anonymous testing of HIV, as recommended by WHO since 1989 [17]. Furthermore, the ANC survey protocol was approved by the Centers of Disease Control and Prevention (CDC, Atlanta, USA) ethics committee.

We received authorization to access the data sets from the authorities of the Rwandan National Institute of Statistics and the Rwanda Treatment and Research Aids Center

In addition, we received ethical exemption from Université Laval ethics committee because our research concerned entirely anonymised data.

\section{RESULTS}

A total of 13745 ANC attendees and 5641 women recruited in the DHS were included in the study: $95.2 \%$ of all 
new pregnant women registered for antenatal consultation in 30 sentinel sites participated in the 2005 ANC survey [16], whereas $97.3 \%$ of eligible women of the general population accepted to give a blood sample for HIV testing [15].

Characteristics of both populations are presented in Table 1. While the proportions of women living in the capital city were similar in both populations: $8 \%$ for DHS population versus 7\% for ANC population, in other urban areas the proportion of DHS women was $9 \%$ compared with $40 \%$ for the ANC population. The respective proportions for rural areas were $83 \%$ versus $53 \%(\mathrm{p}<0.001)$. Median age was similar in both populations (26 years): but younger and older women (15-19; 40-49 years) were more represented in the DHS than in the ANC population, whereas women aged between 20 to 39 years were more represented among pregnant women $(\mathrm{p}<0.001)$.
Single women and women living alone (including separated, divorced and widowed) were much more represented in the DHS than in the ANC population $(\mathrm{p}<0.001)$.

There are more women in the general population than among pregnant women who have high school level or more, particularly in the Capital city (38\% versus $20 \%$ ).

Overall HIV prevalence among DHS women was 3.6\% (95\% CI: 3.1-4.1\%), lower than that estimated in ANC attendees, $4.1 \%$ (95\% CI: 3.8-4.5\%).

Table 2 shows HIV prevalence in the two surveys stratified by geographical areas. For both, estimates of HIV prevalence were very different between areas; the highest prevalence is noted in the Capital city, the lowest in rural areas. In the Capital, HIV prevalence estimated was lower in

Table 1. Socio Demographic Characteristics of Demographic and Health Survey (DHS) and Sentinel Surveillance (ANC) Women by Geographic Area

\begin{tabular}{|c|c|c|c|c|c|c|c|c|}
\hline \multirow{3}{*}{ Characteristics } & \multirow{2}{*}{\multicolumn{2}{|c|}{$\begin{array}{c}\text { The Capital City (Kigali) } \\
\text { No (\%) }\end{array}$}} & \multirow{2}{*}{\multicolumn{2}{|c|}{$\begin{array}{c}\text { Other Urban Areas } \\
\text { No }(\%)\end{array}$}} & \multirow{2}{*}{\multicolumn{2}{|c|}{$\begin{array}{c}\text { Rural Areas } \\
\text { No }(\%)\end{array}$}} & \multicolumn{2}{|c|}{ Total $^{*}$} \\
\hline & & & & & & & \multirow{2}{*}{\begin{tabular}{l}
\multicolumn{1}{c}{ No (\%) } \\
DHS \\
Women \\
5641
\end{tabular}} & \multirow{2}{*}{$\begin{array}{l}\text { No (\%) } \\
\text { ANC } \\
\text { Women } \\
13745\end{array}$} \\
\hline & $\begin{array}{l}\text { DHS } \\
\text { Women } \\
437(8)\end{array}$ & $\begin{array}{l}\text { ANC } \\
\text { Women } \\
1008 \text { (7) }\end{array}$ & $\begin{array}{l}\text { DHS } \\
\text { Women } \\
504(9)\end{array}$ & $\begin{array}{l}\text { ANC } \\
\text { Women } \\
5473(40)\end{array}$ & $\begin{array}{l}\text { DHS } \\
\text { Women } \\
\mathbf{4 7 0 0}(83)\end{array}$ & $\begin{array}{l}\text { ANC } \\
\text { Women } \\
7264(53)\end{array}$ & & \\
\hline Median age & 25 & 24 & 26 & 27 & 27 & 27 & 26 & 26 \\
\hline Interquartile range & $19-32$ & $21-29$ & $20-35$ & $23-32$ & $20-36$ & $23-32$ & $20-36$ & $23-32$ \\
\hline \multicolumn{9}{|l|}{ Age group (year) } \\
\hline $15-19$ & $112(26)$ & $136(14)$ & $121(24)$ & $328(4)$ & $1085(23)$ & $315(4)$ & $1318(23)$ & $779(6)$ \\
\hline $20-24$ & $104(24)$ & $396(39)$ & $98(20)$ & $1673(31)$ & $936(20)$ & $2300(32)$ & $1138(20)$ & $4369(32)$ \\
\hline $25-29$ & $84(19)$ & $252(25)$ & $75(15)$ & $1474(27)$ & $668(14)$ & $1924(27)$ & $827(15)$ & $3650(27)$ \\
\hline $30-34$ & $59(13)$ & $139(14)$ & $81(16)$ & $1066(20)$ & $665(14)$ & 1357 (19) & 805 (14) & $2562(19)$ \\
\hline $35-39$ & $35(8)$ & $69(6)$ & $52(10)$ & $615(11)$ & $448(10)$ & $858(12)$ & $535(10)$ & $1535(11)$ \\
\hline $40-49$ & $43(10)$ & $21(2)$ & $75(15)$ & $270(5)$ & 897 (19) & $437(6)$ & $1016(18)$ & $728(5)$ \\
\hline \multicolumn{9}{|l|}{ Marital status } \\
\hline Single & $224(51)$ & $115(11)$ & $227(45)$ & $335(6)$ & $1728(37)$ & $179(2)$ & $2179(39)$ & $629(5)$ \\
\hline Legally married & $82(19)$ & $235(23)$ & $146(29)$ & $2435(45)$ & $1383(29)$ & $3402(47)$ & $1611(28)$ & $6072(44)$ \\
\hline Cohabitation & $58(13)$ & $623(63)$ & $69(14)$ & $2599(47)$ & $976(21)$ & 3555 (49) & $1103(20)$ & $6777(49)$ \\
\hline Widowed, separated & $67(15)$ & $34(3)$ & $59(12)$ & $70(1)$ & $561(12)$ & $76(1)$ & $688(12)$ & $180(1)$ \\
\hline Divorced & $5(1)$ & $1(0)$ & $1(0)$ & $25(0)$ & $50(1)$ & $42(1)$ & $57(1)$ & $68(0)$ \\
\hline \multicolumn{9}{|l|}{ Education level } \\
\hline None/Primary & $272(62)$ & $795(80)$ & $388(77)$ & $495(91)$ & $4423(94)$ & 7015 (97) & $5083(90)$ & $12761(93)$ \\
\hline Secondary/Higher & $165(38)$ & $200(20)$ & $116(23)$ & $483(9)$ & $277(6)$ & $213(3)$ & $558(10)$ & $896(7)$ \\
\hline \multicolumn{9}{|l|}{ Number of children } \\
\hline 0 & $203(47)$ & $337(34)$ & $207(41)$ & $1148(21)$ & $1728(37)$ & $1426(20)$ & $2138(38)$ & $2911(22)$ \\
\hline 1 & $54(12)$ & $257(25)$ & $48(9)$ & $980(18)$ & $434(9)$ & $1194(17)$ & $536(10)$ & $2431(18)$ \\
\hline $2-3$ & $88(20)$ & $241(24)$ & $93(19)$ & $1501(28)$ & $842(18)$ & $1980(27)$ & $1023(18)$ & $3722(27)$ \\
\hline $4-5$ & $60(14)$ & $119(12)$ & $79(16)$ & $1033(19)$ & $736(16)$ & $1465(20)$ & $875(15)$ & 2617 (19) \\
\hline
\end{tabular}


Table 2. HIV Prevalence Among DHS and ANC Women by Geographic Area

\begin{tabular}{|c|c|c|c|c|c|c|}
\hline \multirow[t]{3}{*}{ Characteristics } & \multicolumn{2}{|c|}{ The Capital City (Kigali) } & \multicolumn{2}{|c|}{ Other Urban Areas } & \multicolumn{2}{|c|}{ Rural areas } \\
\hline & \multicolumn{2}{|c|}{ HIV+ve (\%) } & \multicolumn{2}{|c|}{ HIV+ve (\%) } & \multicolumn{2}{|c|}{ HIV+ ve (\%) } \\
\hline & $\begin{array}{l}\text { DHS } \\
\text { Women } \\
\text { N=437 (8) }\end{array}$ & $\begin{array}{l}\text { ANC } \\
\text { Women } \\
\text { N=1008 (7) }\end{array}$ & $\begin{array}{l}\text { DHS } \\
\text { Women } \\
\text { N=504 (9) }\end{array}$ & $\begin{array}{l}\text { ANC } \\
\text { Women } \\
\text { N=5473(40) }\end{array}$ & $\begin{array}{l}\text { DHS } \\
\text { Women } \\
\text { N=4700 (83) }\end{array}$ & $\begin{array}{l}\text { ANC } \\
\text { Women } \\
\text { N=7264 (53) }\end{array}$ \\
\hline Overall prevalence & $42(9.5)$ & $129(12.8)$ & $38(7.7)$ & $275(5)$ & $123(2.6)$ & $162(2.2)$ \\
\hline Prevalence standardized ${ }^{\mathrm{a}}$ & 9.5 & 13.2 & 7.7 & 5.6 & 2.6 & 2.5 \\
\hline \multicolumn{7}{|l|}{ Age group (year) } \\
\hline $15-19$ & $1(1.6)$ & $11(8.1)$ & $1(0.6)$ & $13(3.9)$ & $6(0.6)$ & $5(1.5)$ \\
\hline $20-24$ & $10(10.13)$ & $44(11.1)$ & $4(4.7)$ & $64(3.8)$ & $13(1.5)$ & $45(1.9)$ \\
\hline $25-29$ & $4(5.2)$ & $37(14.7)$ & $7(9.8)$ & $71(4.8)$ & $15(2.4)$ & $36(1.8)$ \\
\hline $30-34$ & $8(14.1)$ & $26(18.7)$ & $8(10.1)$ & $72(6.7)$ & $30(4.6)$ & $50(3.6)$ \\
\hline $35-39$ & $9(25.6)$ & $10(16.1)$ & $8(16.5)$ & $44(7.1)$ & $19(4.2)$ & $17(1.9)$ \\
\hline $40-49$ & $7(17.5)$ & $1(4.7)$ & $9(12.3)$ & $9(3.3)$ & $37(4.1)$ & $8(1.8)$ \\
\hline$X^{2}(d f=5)$ & $25.41\left(p=0.001^{*}\right)$ & $10.67(p=0.06)$ & $18.81\left(p=0.002^{*}\right)$ & $20.06\left(p=0.001^{*}\right)$ & $46.03\left(p<0.001^{*}\right)$ & $16.18\left(p=0.006^{*}\right)$ \\
\hline \multicolumn{7}{|l|}{ Marital status } \\
\hline Single & $10(4.7)$ & $21(18.2)$ & $5(2.3)$ & $18(5.3)$ & $18(1.1)$ & $8(4.4)$ \\
\hline Married & $4(5.8)$ & $17(7.2)$ & $6(4.5)$ & $76(3.1)$ & $29(2.1)$ & $60(1.7)$ \\
\hline Cohabitation & $6(10.6)$ & $74(11.8)$ & $10(15.5)$ & $163(6.2)$ & $18(1.9)$ & $89(2.5)$ \\
\hline $\begin{array}{l}\text { Separated/Divorced/ } \\
\text { Widowed }\end{array}$ & $20(27.8)$ & $17(48.6)$ & $16(26.6)$ & $16(16.8)$ & $56(9.2)$ & $5(4.2)$ \\
\hline$X^{2}(d f=3)$ & $35.62\left(p<0.001^{*}\right)$ & $50.20\left(p<0.001^{*}\right)$ & $47.92\left(p<0.001^{*}\right)$ & $55.12\left(p<0.001^{*}\right)$ & $122.52\left(p<0.001^{*}\right)$ & $10.89\left(p=0.012^{*}\right)$ \\
\hline \multicolumn{7}{|l|}{ Education level } \\
\hline No education/Primary & $26(9.8)$ & $108(13.6)$ & $29(7.5)$ & $238(4.8)$ & $110(2.5)$ & $150(2.1)$ \\
\hline Secondary/Higher & $15(9.1)$ & $19(9.5)$ & $9(8.4)$ & $32(6.6)$ & $11(4.3)$ & $11(5.1)$ \\
\hline$X^{2}(d f=1)$ & $0.05(p=0.813)$ & $2.3(p=0.12)$ & $0.09(p=0.757)$ & $3.08(p=0.07)$ & $3.18(p=0.074)$ & $8.69\left(p=0.003^{*}\right)$ \\
\hline \multicolumn{7}{|l|}{ Number of children } \\
\hline 0 & $9(4.5)$ & $26(7.7)$ & $4(1.9)$ & $36(3.1)$ & $17(1.0)$ & $21(1.4)$ \\
\hline 1 & $6(11.7)$ & $40(15.6)$ & $4(9.2)$ & $49(5)$ & $16(3.8)$ & $29(2.4)$ \\
\hline $2-3$ & $12(14.4)$ & $37(13.4)$ & $14(15.1)$ & $89(5.9)$ & $39(4.7)$ & $49(2.5)$ \\
\hline $4-5$ & $10(18.2)$ & 19(15.9) & $9(11.4)$ & $66(6.3)$ & $21(2.9)$ & $45(3.1)$ \\
\hline $6+$ & $2(8.5)$ & $5(10.6)$ & $7(9.6)$ & $23(3.2)$ & $26(2.8)$ & $16(1.4)$ \\
\hline$X^{2}(d f=4)$ & $14\left(p=0.007^{*}\right)$ & $12.31\left(p=0.01^{*}\right)$ & $18.75\left(p=0.009^{*}\right)$ & $20.01\left(p=0.005^{*}\right)$ & $35.54\left(p<0.001^{*}\right)$ & $12.75\left(p=0.012^{*}\right)$ \\
\hline
\end{tabular}

${ }^{\mathrm{a}} \mathrm{HIV}$ prevalence among pregnant women in each geographical area directly standardised to the distribution of all variables (age, marital status, education, parity) of DHS women. df: Degree of freedom.

*Statistically significant.

DHS women than in ANC attendees: 9.5\% (95\% CI: 6.9$12.4)$ versus $12.8 \%$ (95\% CI: 10.7-14.9). In other urban areas, the prevalence estimated among ANC attendees was lower than in the DHS women: $5 \%$ (95\% CI: 4.4-5.6\%) versus $7.7 \%$ (95\% CI: 5.2-9.9) whereas in rural areas, the DHS prevalence estimate was $2.2 \% \quad(95 \%$ CI: $1.9-2.7)$ compared to $2.6 \%$ (95 CI: 2.2-3.1) for ANC prevalence.

Standardization based on all variables (age, area, marital status, education, parity) into each area results in an overall HIV prevalence of $13.3 \%$ in ANC women living in the capital city, $5.6 \%$ for those in other urban areas and $2.5 \%$ for $\mathrm{ANC}$ women living in rural area.

Table 3 shows the comparison between HIV prevalence in the two populations. ANC surveillance slightly overestimated the overall HIV prevalence in DHS women. The overall crude prevalence ratio (PR) was 1.13 (95\% CI: 0.97-1.33).

Comparison of HIV prevalence by each category of socio-demographic characteristics reveals that HIV prevalence was higher among women aged 15-24 years in 
Table 3. Comparison of HIV Prevalence in ANC and DHS Women

\begin{tabular}{|c|c|c|c|c|c|c|}
\hline & $\begin{array}{c}\text { ANC } \\
\text { Women } \\
\text { HIV+ve (n) }\end{array}$ & $\begin{array}{c}\text { DHS } \\
\text { Women } \\
\text { HIV+ve \% (n) }\end{array}$ & $\begin{array}{c}\text { Crude Prevalence } \\
\text { Ratio Comparing } \\
\text { ANC and DHS } \\
\text { Women } \\
(95 \% C I)\end{array}$ & $p$ & $\begin{array}{c}\text { Adjusted Prevalence } \\
\text { Ratio } \\
\text { comparing } \\
\text { ANC and DHS } \\
\text { Women }{ }^{* *} \\
(95 \% C I)\end{array}$ & $p$ \\
\hline Overall & $4.1(563)$ & $3.6(203)$ & $1.13[0.97-1.33]$ & 0.103 & & \\
\hline Age standardised ${ }^{\mathrm{a}}$ & 3.9 & 3.6 & & & & \\
\hline 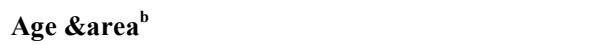 & 3.1 & 3.6 & & & & \\
\hline $\begin{array}{l}\text { Age\&area\&marital } \\
\text { status\&education\&parity }\end{array}$ & 3.6 & 3.6 & & & & \\
\hline \multicolumn{7}{|l|}{ Age group (year): } \\
\hline $15-24$ & $3.5(182)$ & $1.5(38)$ & $2.30[1.62-3.25]$ & $<0.0001^{*}$ & $2.29[1.51-3.46]$ & $<0.0001^{*}$ \\
\hline $25-29$ & $3.9(144)$ & $3.3(27)$ & $1.18[0.79-1.77]$ & 0.3987 & $1.56[0.96-2.53]$ & 0.0674 \\
\hline $30-34$ & $5.7(148)$ & $5.9(47)$ & $0.97[0.71-1.34]$ & 0.8980 & $1.46[0.95-2.27]$ & 0.0836 \\
\hline $35-49$ & $3.9(89)$ & $5.9(91)$ & $0.67[0.50-0.89]$ & $0.0064^{*}$ & $1.20[0.76-1.88]$ & 0.4296 \\
\hline \multicolumn{7}{|l|}{ Area } \\
\hline Rural & $2.2(162)$ & $2.6(123)$ & $0.85[0.67-1.07]$ & 0.1795 & $1.50[1.04-2.18]$ & $0.0294^{*}$ \\
\hline Other urban areas & $5(274)$ & $7.7(38)$ & $0.64[0.46-0.89]$ & $0.0085^{*}$ & $1.09[0.72-1.64]$ & 0.6616 \\
\hline Capital & $12.8(129)$ & $9.5(42)$ & $1.34[0.96-1.86]$ & 0.0814 & $2.42[1.61-3.64]$ & $<0.0001^{*}$ \\
\hline \multicolumn{7}{|l|}{ Marital status: } \\
\hline Legally married & $2.5(153)$ & $2.5(41)$ & $0.99[0.71-1.39]$ & 0.9631 & $1.40[0.91-2.16]$ & 0.1243 \\
\hline Cohabitation & $4.8(326)$ & $3.2(36)$ & $1.49[1.06-2.10]$ & $0.0207^{*}$ & $1.84[1.17-2.90]$ & $0.0077^{*}$ \\
\hline Living alone (separated, divorced, widowed, single) & $9.7(85)$ & $4.3(127)$ & $2.23[1.71-2.90]$ & $<0.0001^{*}$ & $1.54[1.10-2.15]$ & $0.0104^{*}$ \\
\hline \multicolumn{7}{|l|}{ Parity } \\
\hline Nulliparous & $2.8(83)$ & $1.4(30)$ & $1.96[1.30-2.96]$ & 0.0012 & $2.12[1.23-3.63]$ & $0.0062^{*}$ \\
\hline Parity $1+$ & $4.3(467)$ & $4.9(170)$ & $0.89[0.75-1.05]$ & 0.1815 & $1.18[0.91-1.54]$ & 0.1988 \\
\hline \multicolumn{7}{|l|}{ Education } \\
\hline None/Primary & $3.8(429)$ & $3.3(166)$ & $1.18[0.99-1.40]$ & 0.0548 & $1.56[1.15-2.12]$ & $0.0040^{*}$ \\
\hline Secondary/higher & $6.9(62)$ & $6.6(36)$ & $1.05[0.71-1.56]$ & 0.7903 & $1.60[1.03-2.50]$ & $0.0351^{*}$ \\
\hline
\end{tabular}

the ANC survey compared to the DHS (adjusted prevalence ratio (APR): $2.29 \mathrm{p}=0.001$ ).

According to the area of residence, APR was higher among ANC women than in DHS women, specifically in rural areas and in the Capital city $(p=0.029$ and $p<0.0001$ respectively).

Concerning marital status, results show that ANC attendees who were not legally married were more often HIV-positive than DHS women with the same marital status $(p=0.0077$ for cohabiting women and $p=0.0104$ for women living alone, respectively).

Only standardization based on all variables gave an overall HIV prevalence of $3.6 \%$ in ANC women, similar to that measured in DHS population.

\section{DISCUSSION}

The results of this study show that in 2005, HIV sentinel surveillance among pregnant women slightly overestimated overall HIV prevalence seen in DHS women $(\mathrm{PR}=1.13$; $\mathrm{p}=0.103$ ).

Opposite results were showed in some sub Saharan Africa countries [5, 6, 18], whereas similar results were demonstrated in 1998 in Ethiopia [19] and in 2005 in South Africa [3]. The factors presented by the authors of these two studies as explanations of the overestimation of ANC-based estimates do not seem to be applicable to the context of Rwanda. Indeed in the Ethiopian study, the selection bias related to the high-risk women who refused the test in the population based-survey appeared to explain the observed differences [18], whereas the highest use of modern 
contraception was associated with the ANC overestimation in the South Africa study [3]. Related to these two factors, Rwanda DHS data showed a $97.3 \%$ participation rate for HIV testing among women, whereas contraceptive use among sexually active women was $9.6 \%$ in the same study [15]. Comparison made between HIV prevalence reported from a household survey and an antenatal survey conducted in Rwanda in 1997 and in 1998, respectively, showed that HIV prevalence among women of the general population was higher than among ANC women (11,3\% versus $9,5 \%$ respectively) [20].

The results of surveys conducted early after the 1994 genocide in Rwanda need to be interpreted cautiously, due to changes that occurred in the population during this period (mortality and displacement), the consequences of the destruction of health services infrastructure on the quality of the data, and the representativeness of sentinel surveillance system.

In fact, when observing HIV estimates reported in 199798 and those reported a few years later in 2000, when the country was stabilized, health system and other infrastructures strengthened (i.e. expansion of national sentinel surveillance in 2002), HIV prevalence estimated by sentinel surveillance dropped from $9.5 \%$ to $5.2 \%$ [21] whereas that estimated in the general population dropped from $11.3 \%$ to $3.6 \%$ according to the 2005 demographic and health survey [15]

Socio-demographic characteristics differed between both populations, while being associated with HIV prevalence, thus leading to the observed differences in HIV prevalence between ANC women and those from the general population. The main difference was the distribution according to the type of geographic area. Except in the Capital city where the proportion of women was almost similar for both populations (Table 1), in other urban areas, pregnant women were more represented than women of the general population, the reverse situation being observed in rural areas. The over representation of pregnant women in other urban areas is a result of a misclassification of the rural/urban status of pregnant women enrolled in urban sites outside the capital city: in fact, the sites known as urban (out of the Capital) included a small zone which could have all typical characteristics of an urban setting (out of the Capital) whereas the rest of its catchment refers to a rural area. Actually the sites located in other urban areas received more pregnant women from their rural catchment than those from their urban catchment (the similarity of characteristics between ANC women of other urban and rural areas can be seen in Table 1) This situation leads to an underestimation of the actual HIV prevalence among ANC women living in urban areas other than the Capital city. We suggest to add on the variable list collected in the ANC survey, the administrative sector where the pregnant women comes from; that could help to identify if the pregnant women comes from an urban or rural zone of the sentinel site.

The overestimation in the capital city (adjusted prevalence ratio: $2.42 \mathrm{p}=0.0001$ ), could result from a selection bias due to the location of sentinel sites in this area. In fact, the two sentinel facilities are located in areas where stay most of sex workers and truck drivers from Dar Es Salaam and Mombasa (Bilyogo and Gikondo sites), two of the main high-risk groups for HIV infection in sub-Saharan Africa [22-27]. These health facilities could attract a large number of pregnant women from these high-risk groups (sex workers and women having relationships with truck drivers).

A simultaneous standardization of the ANC results for the DHS distribution of all socio-demographic factors common to the two surveys resulted in a $3.6 \%$ overall prevalence estimated for women in the general population from the ANC population data; when we applied this standardization into each geographic area, it resulted in an overestimation in the Capital city and an underestimation in the other urban areas (Table 2).

Despite the differences seen between HIV prevalence measured by the two surveys, sentinel surveillance was a relatively good proxy to estimate overall HIV prevalence among women of reproductive age in Rwanda in 2005. That is partly a result of the extension of sentinel sites established in 2002 which added more rural sites; this reduced the selection bias due to the limit of geographical coverage of sentinel sites. This kind of selection bias was the main bias related to the first sentinel surveillance systems in Africa, which were characterized by an over representation of urban sites [28].

Compared with overall adult HIV prevalence (among both women and men) Rwanda sentinel surveillance overestimates HIV prevalence in the general population $(4.1 \%$ versus 3\%) [15]. This situation is not only for Rwanda; despite improvements and expansion of surveillance systems in recent years [11], antenatal surveillance continues to overestimate adult prevalence in many countries with generalised epidemics [14].

In order to obtain accurate national-level estimates of HIV prevalence from sentinel data, UNAIDS made modifications to different versions of the UNAIDS Estimation and Projection Package (EPP) [29, 30]; however, because of difference in prevalence of HIV between men and women and the lack of male data in current antenatal surveillance, estimates of HIV prevalence from antenatal surveillance will suffer from bias related to the HIV male to- female ratio. In fact, the proportion of women among HIV cases increases over time, especially in sub-Saharan Africa [31]. In their recent work Lowndes et al. showed that in nine West African countries, HIV prevalence was almost always higher among females than males for all marital statuses [32]; also the situation in Rwanda shows that since the beginning of the HIV epidemic, women were more infected than men. The female-to-male ratio was $1.4[15.4$ (HIV prevalence among women):10.8 (HIV prevalence among men)] in 1986 [19] and 1.6 in the 2005 DHS [15]. Thus, the adjustment factor and calibrating parameter applied to antenatal surveillance data should consider the influence of the sex ratio of HIV infection which changes overtime with the stage of the epidemic.

Furthermore, in future, it will be necessary to investigate the potential bias between antenatal and population-based surveys due to the effects of anti-retroviral therapy (ART) on fertility of HIV positive women who consider becoming pregnant, and the impact of family planning services offered to HIV-infected women who do not wish to become pregnant. We do not think that these effects were present at 
the time of our study, as Rwanda started a significant ART program in 2003, only two years before data collection of this study.

In conclusion, our results show that antenatal surveillance overestimated HIV prevalence among women of the general population in Rwanda. This overestimation is due to the difference of distribution of socio-demographic characteristics associated with HIV between antenatal and DHS populations.

Antenatal surveys remain a useful tool to monitor the epidemic, but their results need to be adjusted to better reflect the prevalence in the general adult population of women, while inference from such data to the global prevalence among the total adult population of both sexes may remain difficult, with the temporal changes in the maleto-female ratio in HIV prevalence. Consequently, DHS must also be included in the package of HIV surveillance activities (although on a less regular basis than ANC surveillance), especially to provide information on the HIV epidemiology among men. Considering the impact of highly active antiretroviral therapy era on HIV-related mortality, incidence studies are needed to estimate the magnitude of new cases of HIV and monitor the trends of the epidemic.

\section{ACKNOWLEDGEMENTS}

We are grateful to the staff of the Rwanda National Institute of Statistics, Rwanda treatment and Research Aids Center and National Reference Laboratory for their contributions to the DHS and antenatal surveillance sampling, data collection, data entry, and laboratory testing.

We thank Mohamed Ayad, Bridgette James of Macro International for provision of DHS data, Eric Demers of the Unité de recherche en santé des populations, Centre hospitalier affilié universitaire de Québec, for statistical support and Danièle Morneau for english editing.

\section{SPONSORSHIP}

The antenatal sentinel surveillance was funded by the Centers of Disease Control and Prevention (CDC, Atlanta, USA). The Demographic and Health Survey was funded by the following organizations: the United States Agency for International Development (USAID) through the MEA SURE DHS project; the Rwanda National Aids Control Commission through the World Bank Multi country AIDS Program, DFID, UNFPA, GTZ.

Jeanne Françoise Kayibanda is supported by a $\mathrm{PhD}$ scholarship from the Programme Canadien des bourses de la Francophonie

Michel Alary was a National Researcher of the Fonds de la Recherche en Santé du Québec (Grant \# 8722).

\section{REFERENCES}

[1] UNAIDS/WHO. Guidelines for conducting HIV sentinel serosurveys among pregnant women and other groups. Geneva, WHO/UNAIDS; 2003, available at: http://data.unaids.org/Publica tions/IRC-pub06/JC95 4-ANC-serosurveys Guidelines en.pdf (accessed $22^{\text {nd }}$ September 2010).

[2] United States Bureau of Census. HIV/AIDS surveillance data base. Bureau of the Census, Washington: http://www.census.gov/ipc/ww w/hiv/

[3] Rice BD, Bätzing-Feigenbaum J, Hosegood V, et al. Population and antenatal-based HIV prevalence estimates in a high contracep- ting female population in rural South Africa. BMC Public Health 2007; 7: 160 .

[4] Montana LS, Mishra V, Hong R. Comparison of HIV prevalence estimates from antenatal care surveillance and population-based surveys in sub-Saharan Africa. Sex Transm Infect 2008; 84 (Suppl I): i78-i84

[5] Fylkenes K, Ndlovu Z, Musonda R, et al. Studying dynamics of the HIV epidemic: population based data compared with sentinel surveillance in Zambia. AIDS 1998; 12: 1227-34.

[6] Changalucha J, Grosskurth H, Mwita W, et al. Comparison of HIV prevalences in community-based and antenatal clinic surveys in rural Mwanza, Tanzania. AIDS 2002; 16: 661-5.

[7] Walker N, Grassly NC, Garnett GP, et al. Estimating the global burden of HIV/AIDS: what do we really know about the HIV pandemic? Lancet 2004; 363: 2180-5.

[8] Kayirangwa E, Hanson, J, Munyakazi, L, et al. Current trends in Rwanda's HIV/AIDS epidemic. Sex Transm Infect 2006; 82 (Suppl I): i27-i31.

[9] Garcia-Calleja JM, Zaniewski E, Ghys PD, et al. A global analysis of trends in the quality of HIV sero-surveillance. Sex Transm Infect 2004; 80:i25-i30.

[10] UNAIDS: Report on the global AIDS epidemic. UNAIDS/08.25E / JC1510E, august 2008.

[11] Diaz T, Garcia-Calleja JM, Ghys PD, et al. Advances and future directions in HIV surveillance in low- and middle-income countries. Curr Opin HIV AIDS 2009; 4(4): 253-9.

[12] Boerma JT, Ghys PD, Walker N. Estimates of HIV-1 prevalence from national population-based surveys as a new gold standard. Lancet 2003; 362: 1929-31.

[13] UNAIDS/WHO Working group on Global HIV/AIDS and STI surveillance: Guidelines for measuring national HIV prevalence in population-based surveys. Geneva 2005.

[14] Gouws E, Mishra V, Fowler TB. Comparison of adult HIV prevalence from national population-based surveys and antenatal clinic surveillance in countries with generalised epidemics: implications for calibrating surveillance data. Sex Transm Infect 2008 ; 84 (Suppl I): i17-i23.

[15] National Institute of Statistics (INSR) and ORC Macro. Rwanda Demographic and Health Survey 2005. Calverton, Maryland, U.S.A.: INSR and ORC Macro 2006.

[16] Ministry of Health of Rwanda, Treatment and Research Aids Center. Tracking HIV Infection by sentinel site among pregnant women attending antenatal clinics, Rwanda 2005. Available at: http://www.tracrwanda.org.rw/reports_pdf/rapport_de_serosurveill ance 2005.pdf (accessed 16th October 2008).

[17] WHO: Unlinked anonymous screening for the public health surveillance of HIV infections: proposed international guidelines. Geneva, 1989: 4, available at: http://whqlibdoc.who.int/hq/1989/G PA_SFI_89.3.pdf (accessed 22 ${ }^{\text {nd }}$ September 2010).

[18] Glynn JR, Buvé A, Caraël $\mathrm{M}$, et al. Factors influencing the difference in HIV prevalence between antenatal clinic and general population in sub-Saharan Africa. AIDS 2001; 15: 1717-25.

[19] Fontanet A, Messele T, Dejene A, et al. Age- and sex-specific HIV-1 prevalence in the urban community setting of Addis Ababa, Ethiopia. AIDS 1998; 12: 315-22.

[20] Ministry of Health. Annual report. Kigali, Rwanda 2000.

[21] Ministry of Health /Treatment and Research Aids Center. HIV sentinel surveillance among pregnant women attending antenatal clinics, Rwanda, 2002.

[22] Georges AJ, Georges-Courbot MC. Epidemiology of HIV infections in Africa. Rev Prat 1990; 40: 2131-5.

[23] Buzingo T, Alary M, Sokal DC, Saidel T. The prevalence of HIV and risk behavior of prostitutes living in 2 populous regions of Bujumbura (Burundi). Cahier Santé 1997; 7: 355-60.

[24] Bakare RA, Oni AA, Umar US, et al. Pattern of sexually transmitted diseases among commercial sex workers (CSWs) in Ibadan, Nigeria. Afr J Med Med Sci 2002; 31: 243-7.

[25] Nagot N, Ouangre A, Ouedraogo A, et al. Spectrum of commercial sex activity in Burkina Faso: classification model and risk of exposure to HIV. J Acquir Immune Defic Syndr 2002; 29: 517-21.

[26] Mosoko JJ, Macauley IB, Zoungkanyi AC, et al. Human Immunodeficiency Virus Infection and Associated Factors among Specific Population Subgroups in Cameroon. AIDS Behav 2009; 13: 277-87. 
[27] Ramjee G, Gouws E. Prevalence of HIV among truck drivers visiting sex workers in KwaZulu-Natal, South Africa. Sex Transm Dis 2002 ; 29: 44-9.

[28] UNAIDS /WHO: Reconciling Antenatal clinic- based surveillance and population-based survey estimates of HIV prevalence in Subsaharan Africa. Geneva, UNAIDS/WHO 2003. Available at: http://data.unaids.org/UNA-docs/ANC-Population_surveys report en.pdf (accessed 14 $4^{\text {th }}$ october 2010).

[29] Brown T, Grassly NC, Garnett G, et al. Improving projections at the country level: the UNAIDS Estimation and Projection Package 2005. Sex Transm Infect 2006; 82(Suppl 3): iii34-40
[30] UNAIDS/WHO Working Group on Global HIV/AIDS \& STI Surveillance. EPP 2009 HIV epidemic trends in the ART era Generalized epidemics. Available at: http://data.unaids.org/pub/Pre sentation/2009/20090414 epp genepi 2009 en.pdf (accessed 22 $2^{\text {nd }}$ September 2010).

[31] UNAIDS. AIDS epidemic update 2009. Geneva 2009; available at: http://data.unaids.org/pub/Report/2009/JC1700 Epi_Update 2009 en.pdf (accessed $22^{\text {nd }}$ September 2010).

[32] Lowndes CM, Alary M, Belleau M, et al. West Africa HIV/AIDS epidemiology and response synthesis: implications for prevention. Washington, DC, World Bank 2008.

(C) Kayibanda et al.; Licensee Bentham Open.

This is an open access article licensed under the terms of the Creative Commons Attribution Non-Commercial License (http://creativecommons.org/licenses/by-nc/ 3.0/) which permits unrestricted, non-commercial use, distribution and reproduction in any medium, provided the work is properly cited. 